\title{
Dyslipidemia in women: etiology and management
}

This article was published in the following Dove Press journal:

International Journal of Women's Health

7 February 2014

Number of times this article has been viewed

\author{
Binh An P Phan' \\ Peter P Toth ${ }^{2-4}$ \\ 'Loyola University Chicago Stritch \\ School of Medicine, Division of \\ Cardiology, Loyola University Medical \\ Center, Maywood, IL, USA; ${ }^{2} \mathrm{CGH}$ \\ Medical Center, Sterling, ${ }^{3}$ University \\ of Illinois School of Medicine, Peoria, \\ IL, USA; ${ }^{4}$ Michigan State University \\ College of Osteopathic Medicine, \\ East Lansing, MI, USA
}

\begin{abstract}
Dyslipidemia is highly prevalent among women. The management of dyslipidemia is a cornerstone in the prevention of both primary and secondary cardiovascular events, such as myocardial infarction, ischemic stroke, and coronary death. All major international guidelines on the treatment of dyslipidemia recommend similar approaches to the management of dyslipidemia in both men and women. Estrogen replacement therapy should not be considered as a therapeutic option for managing dyslipidemia in women. The reduction of atherogenic lipoprotein burden (reducing low-density lipoprotein cholesterol and non-high-density lipoprotein cholesterol based on risk-stratified thresholds and treatment targets) provided the framework for managing dyslipidemia in the US, Europe, Canada, and elsewhere in the world. Very recently, new guidelines in the US have changed this paradigm, whereby rather than focusing on treatment targets, risk now defines the intensity of treatment with statin therapy, with no specific goals for what level of low-density lipoprotein cholesterol should be attained. It is not clear if this will lead to changes in lipid guidelines in other parts of the world. In the meantime, region-specific guidelines should be followed. Lipid lowering with statin therapy does correlate with reductions in cardiovascular event rates in women. The clinical impact of treating dyslipidemias in women with nonstatin drugs (eg, fibrates, nicotinic acid, bile acid-binding resins, omega-3 fish oils) is as yet not determined.
\end{abstract}

Keywords: dyslipidemia, high-density lipoprotein cholesterol, low-density lipoprotein cholesterol, triglycerides, statins

\section{Introduction}

Cardiovascular disease is the leading cause of death for women in the US. ${ }^{1}$ It is estimated that one in every two women die of a heart-related disorder, which represents more deaths than due to cancer, chronic lung conditions, and accidents combined. ${ }^{2}$ While there is a gap of approximately 10 years in mortality rates between women and men, each year the number of cardiovascular deaths in women are similar to those in men. ${ }^{3}$ The risk factors for heart disease such as hypertension and smoking in women are similar to those found for men. Abnormal cholesterol levels with elevated low-density lipoprotein cholesterol (LDL-C) or low high-density lipoprotein cholesterol (HDL-C) have been well established as modifiable risk factors for cardiovascular disease in both men and women. ${ }^{4,5}$ Cross-sectional surveys from the US have shown that up to $20 \%$ of women have hypercholesterolemia, with total cholesterol levels $>240 \mathrm{mg} / \mathrm{dL}$, and a larger number require medical therapy. ${ }^{6}$ A number of randomized controlled trials over the past 25 years have shown that treatment of hypercholesterolemia with statins has reduced cardiovascular events in women with established heart disease. ${ }^{7}$ While similarities exist
Correspondence: Peter P Toth CGH Main Clinic, I0I East Miller Road, Sterling, IL 6I08I, USA

Tel +l 8156325093

Email peter.toth@cghmc.com
International Journal of Women's Health 2014:6 I85-194

Dovepress

http://dx.doi.org/10.2147/IJWH.S38133
185 LY License. The full terms of the License are available at http://creativecommons.org/licenses/by-nd/3.0/. Non-commercial uses of the work are permitted without any further permission from Dove Medical Press limited, provided the work is properly attributed. Permissions beyond the scope of the License are administered by Dove Medical Press Limited. Information on how to request permission may be found at: http://www.dovepress.com/permissions.php 
between men and women in terms of attendant risk associated with abnormal lipoprotein levels, there exist several important biological differences that are unique to women and affect the understanding and management of their lipid disorders. In this review, we address the etiology of dyslipidemia in women, the impact of menopause and hormone replacement therapy (HRT) on lipids and lipoproteins, and emphasize the urgent need to increase screening for and treatment of dyslipidemia in women so as to reduce the risk for cardiovascular morbidity and mortality.

\section{Etiology and pathogenesis of dyslipidemia in women Lipid and lipoprotein primer}

In guidelines around the world, LDL-C is designated as the primary target of therapy in patients with dyslipidemia. ${ }^{8-10}$ LDL-C and non-HDL-C (defined as total cholesterol minus HDL-C, a surrogate measure of total atherogenic lipoprotein burden in serum) targets in patients at risk are risk-stratified (ie, the higher the risk, the lower the LDL-C target). HDL-C levels have an inverse relationship with risk for CHD in both men and women. The lower the HDL-C level, the higher the risk. HDL-C is a remarkably good predictor of CHD risk; however, it is not a target of therapy. Lipoprotein(a) [Lp(a)] is an emerging risk factor that correlates highly with risk for CHD. ${ }^{11,12}$ Apoprotein B100 is the primary apoprotein constituent of atherogenic lipoprotein particles. Apolipoproteins A-I and A-II are the most important apoprotein constituents of HDL particles.

The liver secretes large triglyceride-rich very lowdensity lipoproteins (VLDLs) that aid in the distribution of oxidizable substrate (fatty acids) to systemic tissues. The triglycerides in VLDLs are progressively hydrolyzed by lipoprotein lipase to form intermediate-density lipoproteins and then LDL particles. The liver expresses LDL receptors to clear LDL particles from the circulation. Alternatively, LDLs can be taken up into the subendothelial space and drive atherogenesis.

In the setting of insulin resistance and diabetes mellitus, the activity of lipoprotein lipase is reduced. VLDLs can be incompletely lipolyzed, yielding increased serum levels of VLDL remnants and less formation of intermediate-density lipoproteins and LDLs. As VLDLs and triglycerides accumulate in serum, cholesterol ester transfer protein is activated. This enzyme catalyzes a 1:1 stoichiometric exchange reaction whereby cholesterol esters from HDL and LDL particles are exchanged for triglycerides out of the VLDLs and their remnant particles. In this process, the HDL and LDL particles become progressively more enriched with triglycerides, rendering them more susceptible to lipolysis by hepatic lipase. The HDL particles are catabolized and cleared by the kidney, resulting in lower serum levels of HDL-C. In addition, HDL-C levels decrease further secondary to the following: there are three insulin response elements in the gene for apolipoprotein A-I, and as the liver becomes insulinresistant, it produces less apolipoprotein A-I and engages in less de novo HDL biogenesis; in the setting of insulin resistance, adipocytes produce fewer HDL particles; and chylomicrons produced by the jejunum contain significant amounts of apolipoprotein A-I. ${ }^{13}$ With reduced lipoprotein lipase activity, surface coat constituents containing apolipoprotein A-I are not released. Under normal metabolic conditions, these apolipoprotein A-I moieties are lipidated to form HDL in serum. LDL particles enriched with triglycerides are lipolyzed into smaller, denser, and more numerous particles. Some evidence suggests that these smaller particles are more atherogenic than larger, less dense LDL particles.

\section{Lipoprotein levels across}

\section{a woman's lifetime}

Women experience a number of hormonal changes throughout their lifetime, including those changes associated with puberty, menarche, pregnancy, and menopause. Each of these hormonal perturbations can alter serum lipoprotein levels. ${ }^{14,15}$ At birth, and throughout childhood, serum cholesterol levels are similar between boys and girls. In both sexes, total cholesterol starts around $65 \mathrm{mg} / \mathrm{dL}$ at birth and increases to an average level of $165 \mathrm{mg} / \mathrm{dL}$ by 2 years of age. ${ }^{16}$ While total cholesterol and LDL-C are similar in childhood, there are observed differences in the LDL subclasses. Freedman et al noted in the Bogalusa Heart Study of 918 teenagers aged 10-17 years, that boys had a smaller LDL particle size as compared with girls. ${ }^{17}$ LDL-C levels tend to increase in both men and women after the age of 20 years, but do so more rapidly in men. ${ }^{18}$ Starting during puberty and continuing into early adulthood, HDL-C concentrations decrease in men while staying constant in women. ${ }^{18}$ This HDL-C reduction, beginning at puberty and sustained throughout adulthood, translates into an observed approximately 10-point lower HDL-C level in men as compared with women. ${ }^{8}$ Differences in HDL subclasses have also been noted between male and female adolescents. In the Bogalusa Heart Study, boys and male adolescents had smaller HDL particle size as compared with females. Also, while the levels of large HDL particles generally decrease with age in boys, girls tend to have stable levels of large HDL. ${ }^{19}$ These lipoprotein differences 
between the sexes starting in childhood are hypothesized to be partly responsible for the lower risk of cardiovascular events observed in premenopausal women as compared with age-matched men. ${ }^{15}$

During pregnancy, levels of a number of hormones, including human chorionic gonadotropin hormone, betaestradiol, insulin, and progesterone, are significantly increased. These spikes in hormone levels are associated with increases in total cholesterol, triglycerides, and LDL-C. ${ }^{14,20,21}$ Peak levels of LDL-C occur at 36 weeks during pregnancy. ${ }^{20}$ Similarly, pregnancy is associated with an increase in total HDL-C, HDL2, and apolipoprotein A1 concentration, with maximum levels at week 25 of pregnancy. ${ }^{20,22}$ While there is an increase in HDL-C during pregnancy, levels of HDL-C, in particular HDL-2, and the HDL-C/total cholesterol ratio have been observed to decrease post-pregnancy to levels below prepregnancy levels. ${ }^{23}$ Possible hypothesized mechanisms for the post partum decrease in HDL-C levels include an increase in the pregnancy-related androgen, dehydroepiandrosterone sulfate, which has been associated with low HDL levels in women with polycystic ovary syndrome. Additionally, prolonged insulin resistance and pregnancy-induced diabetes mellitus may explain the observed decline in HDL-C levels following pregnancy. ${ }^{24} \mathrm{Lp}(\mathrm{a})$ is an LDL particle conjugated with apoprotein(a). Serum levels of Lp(a) are genetically determined, and have been found to be significantly elevated in pregnant women as compared with nonpregnant women. ${ }^{22}$ Zechner et al noted that fluctuating changes in Lp(a) levels seen in 42 pregnant women did not mirror the trend normally seen with other lipoproteins during pregnancy. ${ }^{25}$ Additionally, the observed lack of correlation between Lp(a) and pregnancy-related hormones, such as human chorionic gonadotropin hormone, estradiol, and progesterone, suggests independent metabolic control of $\mathrm{Lp}(\mathrm{a})$.

Several epidemiologic studies have shown that postmenopausal women tend to have significantly different lipid profiles as compared with premenopausal women. ${ }^{26,27}$ A number of lipoprotein changes occur that characterize the menopausal transition. ${ }^{28}$ Post-menopausal women have increased levels of LDL-C, total cholesterol, and apolipoprotein B as compared with premenopausal women. In the Framingham Study, investigators documented an increase in cholesterol levels that coincided with menopause, suggesting a causal role of menopause in altering lipid levels. ${ }^{29}$ In addition to a higher LDL-C, investigators have noted menopause to be associated with a transition in LDL particles to more atherogenic smaller and more dense particles. ${ }^{30}$ Total HDL cholesterol and HDL2 also decrease in postmenopausal women. ${ }^{31}$ Elevated Lp(a) levels has been associated with an increased CHD risk and has been reported to increase in women following total hysterectomy and oophorectomy. ${ }^{32}$

Interestingly, no clear association has been documented between natural menopause and changes in Lp(a) levels. ${ }^{33}$ In contrast with the surgical menopause data, Jenner et al showed that postmenopausal women participating in the Framingham Offspring Study had $8 \%$ greater Lp(a) levels than premenopausal women. ${ }^{33}$ The change in lipoprotein profile with the observed increase in total cholesterol, transition to more atherogenic LDL particles, and reduction in HDL-C is believed responsible for the increased risk for cardiovascular events in women after menopause. While most epidemiologic studies have reported changes in cholesterol values in response to menopause, a few studies have shown no association. In a study of 148 premenopausal and 75 postmenopausal Native-American Pima women, Hamman et al showed no significant difference in cholesterol values. This suggests that additional race-specific factors may impact the lipid/lipoprotein changes characteristic of menopause. ${ }^{34}$ While the effects of menopause on cholesterol levels are often described using premenopausal and postmenopausal cohorts of women, true longitudinal studies documenting the effects of age-related cholesterol changes spanning the menopausal period are limited.

\section{Cardiovascular effects of hormone therapy}

Oral contraceptive (OCP) use is known to alter lipoprotein levels depending on the relative concentration and presence of estrogen and progesterone. ${ }^{35}$ The estrogen component found in OCPs tends to increase HDL-C, HDL2, and triglyceride levels and decrease LDL-C levels. Tikkanen et al showed that the increase in HDL and HDL2 is mediated in part by the ability of estrogen to reduce hepatic lipasedependent catabolism of HDL particles. ${ }^{36}$ Conversely, the progesterone component has been noted to have lipoprotein effects that are opposite to those of estrogen. After discontinuation of OCPs, lipoprotein levels appear to return to pretreatment levels. While OCPs have been associated with an increased risk for venous thromboembolism, the risk for cardiovascular events such as myocardial infarction and ischemic stroke appears variable across a number of studies and has not been well established. ${ }^{37}$ In addition, investigators have noted that many women who have been documented to have had a cardiovascular event on OCPs have had traditional cardiac risk factors that would predispose them to CHD events independent of their OCP use. ${ }^{38}$ 
Given the adverse lipoprotein changes and associated risk for CHD observed in women after menopause, there was considerable interest in using HRT to modify the negative cholesterol changes and subsequently improve a woman's cardiac risk profile after menopause. Similar to OCPs, use of HRT is associated with a number of lipoprotein changes. In postmenopausal women, use of HRT with unopposed estrogen is associated with significantly higher HDL-C and $\mathrm{HDL}_{2}$ and lower LDL-C as compared with premenopausal women. ${ }^{39}$ In menopausal women who received HRT, Matthews et al did not find the naturally observed decreases in HDL-C commonly seen in menopause. ${ }^{31}$ On the contrary, they noted increases in apolipoprotein A-I and A-II (the two most important apoprotein constituents of HDL particles) in postmenopausal women taking HRT as compared with women not on HRT. Combination HRT appears to negate the increases in HDL seen with estrogen monotherapy. In the Postmenopausal Estrogen and Progesterone Interventions trial, investigators noted that combination HRT which included progesterone was associated with a significantly smaller increase in HDL-C and triglycerides as compared with estrogen-only HRT. ${ }^{40}$ Changes to LDL particle size have also been observed with combination hormone therapy using estrogen and progesterone. In a small study, Wakatsuki et al showed that 3 months of treatment with estrogen in 24 healthy postmenopausal women resulted in decreased LDL particle size and a change from pattern A (consisting of larger LDL particles) to a more atherogenic pattern $\mathrm{B}$ (consisting of more small and dense LDL particles). ${ }^{41}$ While no clear association has been noted with Lp(a) levels and menopause, in a small study by Soma et al, Lp(a) was shown to decrease in a group of ten women on combination HRT. ${ }^{42}$ In addition to the lipid effect, HRT has been shown to have a number of other beneficial biological effects on the cardiovascular system, including antiplatelet and vasodilatory properties. ${ }^{43}$

Based upon data from epidemiologic studies and early small nonrandomized observational trials, hormone replacement after menopause was believed to reduce the risk of cardiovascular events. In one population study, the Nurse's Health Study, postmenopausal women on HRT had a reduction of $37 \%$ in the relative risk of death as compared with women not on HRT. ${ }^{44}$ Additionally, in 2,270 white women aged 40-69 years of age from the observational Lipid Research Clinics study, estrogen use was associated with a relative risk of cardiovascular death of 0.34 as compared with nonusers. ${ }^{45}$ A meta-analysis of 32 epidemiologic studies published between 1970 and 1992 showed a significant reduction of $35 \%$ in the relative risk of CHD in women on estrogen-only HRT. ${ }^{46}$ In their conclusion, the authors of this meta-analysis recommended use of HRT particularly for women who have had a hysterectomy, have CHD, or are at high risk for cardiovascular disease. While epidemiologic and observational studies suggested a cardiovascular benefit of HRT, data from randomized controlled trials failed to confirm these benefits. In the Heart and Estrogen/Progestin Replacement Study, 2,763 postmenopausal women with CHD were randomized to treatment with conjugated equine estrogen plus medroxyprogesterone acetate or placebo. ${ }^{47}$ After an average follow-up of 4 years, use of HRT was associated with an $11 \%$ reduction in LDL-C and a $10 \%$ increase in HDL-C, but this beneficial lipid change was not associated with significant improvement in CHD events. In the Women's Health Initiative (WHI) study, 10,739 postmenopausal women were randomized to conjugated equine estrogen or placebo. ${ }^{48} \mathrm{After}$ an average follow-up of 6.8 years, the study was stopped early due to a significant increase in the risk of stroke in the estrogen-only treated women, with a hazard ratio for total cardiovascular disease of 1.12 (95\% confidence interval [CI] 1.01-1.24). Based upon these randomized controlled trials, treatment guidelines were subsequently updated with removal of the recommendation for use of HRT in women to prevent CHD events. ${ }^{49}$

\section{Dyslipidemia risk in women}

Multiple lines of evidence have consistently shown an association between increased CHD risk and abnormal levels of lipoproteins. ${ }^{4,50}$ While elevated levels of LDL-C and triglycerides and low levels of HDL-C are independent risk factors for atherosclerotic heart disease, the relative risk associated with each lipoprotein abnormality differs between the sexes. ${ }^{5}$ Women generally have HDL-C levels $10 \mathrm{mg} / \mathrm{dL}$ higher than men. The National Cholesterol Education Panel Adult Treatment Panel suggests that HDL-C levels less than $50 \mathrm{mg} / \mathrm{dL}$ should be considered a CHD risk factor in women; this is $10 \mathrm{mg} / \mathrm{dL}$ higher than the recommended level for men. ${ }^{8}$ Bass et al calculated the WHI risk associated with different lipoprotein abnormalities in 1,405 women aged 50-69 years from the Lipid Research Clinics' Follow-up Study. ${ }^{51}$ They noted that HDL-C and triglycerides were strong predictors of CVD death while LDL-C and total cholesterol were poor predictors in women. While women who had HDL-C levels less than $50 \mathrm{mg} / \mathrm{dL}$ had a $30 \%$ increased risk for cardiovascular mortality, women with triglyceride levels between 200 and $399 \mathrm{mg} / \mathrm{dL}$ had a $65 \%$ increased risk of cardiovascular mortality. In a metaanalysis of 17 population-based prospective studies evaluating the association between elevated triglycerides and CHD risk, 
elevated triglycerides were associated with an approximately $30 \%$ increased risk for men and a $75 \%$ increased risk in women. ${ }^{52}$ Even with adjustment for HDL-C and other risk factors, there remained a significant difference between the relative $\mathrm{CHD}$ risk associated with elevated triglycerides between men and women. Similar to men, LDL particle size also appears to confer CHD risk in women. ${ }^{53}$ Young women with a predominance of small atherogenic LDL-C particles have been shown to have a significantly increased risk for early myocardial infarction. In addition to LDL particle size, Lp(a) has been shown to be an independent predictor of CHD risk in women. In the Heart and Estrogen/Progestin Replacement Study, postmenopausal women with elevated Lp(a) in the highest quartile had a 54\% increase in CHD events as compared with women having $\mathrm{Lp}(\mathrm{a})$ in the lowest quartile. ${ }^{54}$

\section{Management of dyslipidemia in women}

Current cardiovascular disease prevention guidelines for women recommend lifestyle modification as the initial treatment for women with dyslipidemia. ${ }^{49}$ Healthy lifestyle goals to reduce cardiovascular risk in women include smoking cessation, moderate-intensity physical activity on most days of the week for at least 30 minutes per day, and to achieve and maintain a desirable weight. For all women, the American Heart Association step I diet is recommended, with less than $30 \%$ of daily calories from fat, $8 \%-10 \%$ of daily calories from saturated fat, and less than $300 \mathrm{mg} /$ day of cholesterol. For women with established vascular disease, the step II diet is recommended, with less than $7 \%$ of daily calories from saturated fats and less than $200 \mathrm{mg} /$ day of cholesterol. While improvement in progression of atherosclerosis and clinical events has been noted with lifestyle changes in men, similar data are lacking for women. ${ }^{55,56}$ In the Lifestyle Heart Trial, men randomized to an Ornish intensive lifestyle intervention restricted to a $10 \%$ fat vegetarian diet for 5 years had a decrease in coronary diameter stenosis by angiography as compared with a control group. ${ }^{55}$ No women were included in the angiographic analysis for this trial and there have not been any randomized controlled trials published to date showing a benefit of lifestyle intervention in women in terms of atherosclerosis. In the WHI Randomized Controlled Dietary Modification Trial, 48,835 postmenopausal women were randomized to an intensive behavior modification group designed to reduce fat intake and increase fruit/vegetable intake or to a control diet. ${ }^{57}$ After a mean follow-up of 8 years, intensive lifestyle intervention did not reduce the risk of CHD. Recently, the PREDIMED (Prevencion con
Deita Mediterranea) trial showed cardiovascular event reduction with dietary changes. ${ }^{56}$ In this trial, 7,447 people without cardiovascular disease, including 57\% women, were randomized to one of three diets, ie, a Mediterranean diet supplemented with extra virgin olive oil, a Mediterranean diet supplemented with mixed nuts, or a control diet. The two groups assigned to the Mediterranean diet had a 30\% relative risk reduction in the primary composite endpoint of myocardial infarction, stroke, and death from cardiovascular causes. In a subgroup analysis, while the benefit of a Mediterranean diet was seen in men, the female trial participants randomized to the Mediterranean diets failed to show a statistically significant endpoint difference as compared with women on the control diet (hazard ratio $0.73,95 \%$ CI 0.5-1.07).

Multiple randomized controlled trials over the past two decades have shown the benefit of lowering cholesterol with 3-hydroxy-3-methyl-glutaryl coenzyme A reductase inhibitors (statins) in patients with and without vascular disease (Table 1). ${ }^{58-64}$ More recent trials have shown that more aggressive lipid lowering with high-dose statin therapy provides incremental cardiovascular benefit as compared with low-dose or moderate-dose statin therapy. ${ }^{65-67}$ Based on these trials, the National Cholesterol Education Program has recommended statins as the initial preferred therapy in both men and women to treat hypercholesterolemia and lower CHD risk. ${ }^{8}$ Despite this recommendation, there is ongoing controversy regarding whether the cardiovascular benefit observed in men is present and equivalent in magnitude in women, particularly for those women who do not have established heart disease. ${ }^{15}$ The early lipid-lowering trials either did not include women participants or had small numbers of female participants and were not able to show a sex-specific benefit of lipid therapy. ${ }^{59,62,68}$ In an early meta-analysis of five randomized, controlled, primary and secondary prevention statin trials with 30,817 participants, LaRosa et al showed that, overall, statin therapy was associated with a $28 \%$ reduction in LDL-C and an overall $31 \%$ reduction in risk for major coronary events. ${ }^{69}$ The observed risk reduction in major coronary events was noted to be similar between women (29\%) and men (31\%). However, because of insufficient data and the small sample size in several of the trials, the investigators were unable to provide any conclusions regarding a sex-specific mortality benefit of statin therapy. In addition, the investigators did not stratify their analysis by primary versus secondary prevention trials to determine whether there was equivalent benefit between these two groups in women. In a subsequent meta-analysis of 13 lipid-lowering trials, Walsh et $\mathrm{al}^{70}$ assessed the benefit 
Table I Relative risk reductions in women in statin trials

\begin{tabular}{|c|c|c|c|c|c|}
\hline Trial & $\begin{array}{l}\text { Intervention } \\
\text { type }\end{array}$ & Treatment & Women (\%) & Primary endpoint & $\begin{array}{l}\text { Relative risk in } \\
\text { women }(95 \% \mathrm{Cl})\end{array}$ \\
\hline JUPITER ${ }^{71}$ & Primary & $\begin{array}{l}\text { Rosuvastatin } 20 \mathrm{mg} / \text { day } \\
\text { versus placebo }\end{array}$ & $6,80 \mathrm{I}(38)$ & $\begin{array}{l}\mathrm{MI} \text {, stroke, unstable angina, } \\
\mathrm{CHD} \text { death, revascularization }\end{array}$ & $0.54(0.37-0.80)$ \\
\hline AFCAPS/TexCAPS ${ }^{85}$ & Primary & $\begin{array}{l}\text { Lovastatin } 20-40 \mathrm{mg} / \text { day } \\
\text { versus placebo }\end{array}$ & $997(15)$ & $\begin{array}{l}\text { Sudden cardiac death, } \\
\text { MI, unstable angina }\end{array}$ & $0.54(0.22-1.35)$ \\
\hline $4 S^{86}$ & Secondary & $\begin{array}{l}\text { Simvastatin } 20-40 \mathrm{mg} / \text { day } \\
\text { versus placebo }\end{array}$ & $827(19)$ & $\begin{array}{l}\text { All-cause mortality, } \\
\text { CHD death }\end{array}$ & $1.16(0.68-1.99)$ \\
\hline CARE $^{87}$ & Secondary & $\begin{array}{l}\text { Pravastatin } 40 \mathrm{mg} / \text { day } \\
\text { versus placebo }\end{array}$ & $576(14)$ & $\mathrm{CHD}$ death, $\mathrm{MI}$ & $0.57(0.34-0.96)$ \\
\hline LIPID ${ }^{88}$ & Secondary & $\begin{array}{l}\text { Pravastatin } 40 \mathrm{mg} / \text { day } \\
\text { versus placebo }\end{array}$ & $1,516(17)$ & CHD death, MI & $0.89(0.67-1.18)$ \\
\hline $\mathrm{HPS}^{89}$ & Primary/secondary & $\begin{array}{l}\text { Simvastatin } 40 \mathrm{mg} / \mathrm{day} \\
\text { versus placebo }\end{array}$ & $5,082(25)$ & $\begin{array}{l}\text { CHD death, } \mathrm{MI} \text {, stroke, } \\
\text { revascularization }\end{array}$ & $0.80(0.70-0.92)$ \\
\hline
\end{tabular}

Abbreviations: CHD, coronary heart disease; Cl, confidence interval; JUPITER, Justification for the Use of Statins in Prevention, an Intervention Trial Evaluating Rosuvastatin; AFCAPS/TexCAPS, Air Force/Texas Coronary Atherosclerosis Prevention Study; 4S, Scandinavian Simvastatin Survival Study; CARE, Cholesterol and Recurrent Events Trial; LIPID, Long-term Intervention with Pravastatin in Ischemic Disease Study; HPS, Heart Protection Study; MI, myocardial infarction.

of lipid therapy on CHD events and mortality in women with and without established cardiovascular disease..$^{49}$ The 13 trials in their analysis included 17,891 women, with one third having a diagnosis of CHD. In women who had CHD, treatment with lipid-lowering agents was associated with a $29 \%$ reduction in nonfatal myocardial infarction (relative risk $0.71,95 \%$ CI $0.58-0.87$ ) and a $26 \%$ reduction in CHD mortality (relative risk $0.74,95 \%$ CI $0.55-1.00$ ). In women without established CHD, lipid therapy was not associated with a significant reduction in nonfatal myocardial infarction (relative risk $0.61,95 \% \mathrm{CI} 0.22-1.68$ ) or cardiovascular mortality (relative risk $1.07,95 \% \mathrm{CI} 0.47-2.40$ ). Total mortality was not lowered in either the primary or secondary prevention groups for women. The lack of a significant benefit for CHD events or CHD mortality in women demonstrated by this meta-analysis of primary prevention may be explained by the small number of events ( 21 total CHD deaths, 14 total nonfatal myocardial infarction) in the lower-risk primary prevention population and the relative short duration of follow-up in the studies (2.8-6 years).

More recently, the cardiovascular benefit of statin therapy in primary prevention of CHD in women was again investigated in a post hoc analysis of the Justification for the use of Statins in Prevention: An Intervention Trial Evaluating Rosuvastatin (JUPITER) ${ }^{71}$ In JUPITER, 6,801 women and 11,001 men with elevated high-sensitivity C-reactive protein greater than $2 \mathrm{mg} / \mathrm{L}$ and LDL-C less than $130 \mathrm{mg} / \mathrm{dL}$ were randomized to rosuvastatin or placebo. Overall, the study showed a $44 \%$ reduction in the primary composite endpoint of myocardial infarction, stroke, revascularization, unstable angina, or CHD death. In women, while there was a significant benefit observed for reduction in the endpoint of revascularization/unstable angina (hazard ratio $0.24,95 \% \mathrm{CI}$ $0.11-0.51$ ), there was no significant reduction in nonfatal myocardial infarction (hazard ratio $0.56,95 \%$ CI $0.24-1.33$ ) or CHD death (hazard ratio $0.73,95 \%$ CI $0.48-1.13$ ). While the National Cholesterol Education Program Adult Treatment Panel recommends statin therapy as the primary treatment in both men and women with hypercholesterolemia, it does acknowledge the weakness of the available data on primary prevention for women. ${ }^{8}$ The National Cholesterol Education Program Adult Treatment Panel guidelines note that the rationale for recommending statin therapy for primary prevention is based on extrapolation of the benefit observed in men with similar risk, although no clear significant outcomes trials exist in this risk category for women.

The efficacy of other lipid-lowering medications in reducing the risk of cardiovascular events is highly questionable. Gemfibrozil therapy was evaluated in both primary and secondary prevention settings in the Helsinki Heart Study and the Veterans Administration High Density Lipoprotein Intervention trial, and both met their primary composite endpoint. Unfortunately, neither trial included women. ${ }^{68,72}$ Among patients with diabetes mellitus, fenofibrate did not provide a statistically significant reduction in cardiovascular events when used either as monotherapy or in combination with a statin. ${ }^{73,74}$ Two recent niacin/statin trials that included women were both negative. ${ }^{75,76}$ The addition of high-dose niacin therapy to a statin background provided no incremental reduction in risk for cardiovascular events. The only outcomes trial that used a bile acid-binding resin (cholestyramine) did not include women. ${ }^{77}$ In the IMPROVE-IT (IMProved Reduction of Outcomes: Vytorin Efficacy International Trial) trial, men and women who are 
status post acute coronary syndrome are being randomized to therapy with simvastatin versus simvastatin and ezetimibe. ${ }^{78}$ This trial is expected to achieve completion in 2014. Among men and women with chronic kidney disease (mean glomerular filtration rate $27 \mathrm{~mL} /$ minute $/ 1.73 \mathrm{~m}^{2}$ ), the combination of simvastatin/ezetimibe did reduce the risk of cardiovascular events in patients not receiving dialysis. ${ }^{79}$ Consequently, at the present time, there is no outcomes-based evidence to support the use of adjuvant lipid-lowering therapy over and above statin therapy in women, with the exception of those with chronic kidney disease and not on dialysis. Nonstatin therapy can be considered in women as first-line therapy if they are statin-intolerant (eg, develop myalgia, motor weakness, evidence of myopathy with elevated serum creatine kinase, or elevated serum transaminase or bilirubin levels). In women with severe hypertriglyceridemia (serum triglycerides $>500$ $\mathrm{mg} / \mathrm{dL}$ ), the risk for pancreatitis is substantially increased. In these patients, it is important to reduce serum triglycerides by lifestyle modification (exercise and smoking cessation which can relieve insulin resistance and lower triglycerides), restrict intake of saturated fat, and pharmacologic intervention. Consideration should be given to fenofibrate and high-dose omega-3 fish oil therapy, because these agents substantially reduce serum triglyceride levels. However, they have not been shown to reduce the risk of pancreatitis in patients with severe hypertriglyceridemia. Gemfibrozil should not be combined with a statin because of the significantly increased risk for myopathy and rhabdomyolysis. ${ }^{80}$ Gemfibrozil reduces the glucuronidation and elimination of statins. ${ }^{81,82}$

The recently released 2013 American College of Cardiology/American Heart Association guideline on the treatment of blood cholesterol to reduce atherosclerotic cardiovascular risk in adults has moved away from LDL-C treatment thresholds and targets. ${ }^{83}$ Instead, it advocates use of the new pooled cohort risk equations to estimate risk in patients in the primary prevention setting. ${ }^{84}$ Among men and women with established clinical atherosclerotic cardiovascular disease (acute coronary syndromes [myocardial infarction or unstable angina] or a history of revascularization, stroke, transient ischemic attacks or peripheral arterial disease, without heart failure or receiving hemodialysis), daily treatment with high-intensity statin therapy (atorvastatin 40-80 mg or rosuvastatin 20-40 mg) should be initiated. Those with primary elevations of LDL cholesterol $\geq 190 \mathrm{mg} / \mathrm{dL}$ should also be treated with high-intensity statin therapy because these patients are likely to have familial hypercholesterolemia. Patients with type 1 or 2 diabetes, aged 40-75 years, with LDL-C 70-189 mg/dL, and without clinical atherosclerotic cardiovascular disease should be treated with moderate-intensity statin therapy (atorvastatin 10-20 $\mathrm{mg}$, rosuvastatin 5-10 mg, simvastatin $20-40 \mathrm{mg}$, pravastatin 40-80 mg, lovastatin $40 \mathrm{mg}$, fluvastatin XL $80 \mathrm{mg}$, fluvastatin $40 \mathrm{mg}$ twice daily, or pitavastatin 2-4 mg). Treatment with a statin is not recommended if the 10-year estimated risk for atherosclerotic cardiovascular disease-based events is $<7.5 \%$ and the patient is 40-75 years of age with an LDL-C of 70-189 $\mathrm{mg} / \mathrm{dL}$ and has not previously been diagnosed with diabetes mellitus or CVD. However, if such a patient has a risk that exceeds $7.5 \%$, then moderate-intensity to high-intensity statin therapy is recommended. It was also recommended that, in patients who are intolerant of statin therapy because of myalgia, consideration should be given to: temporarily discontinuing the statin; evaluating the patient for thyroid, renal, or hepatic dysfunction; ruling out polymyalgia rheumatica, drug-related myopathy, vitamin D deficiency, or primary muscle disorders (including mitochondriopathy); and then restarting the statin at a lower dose or switching to another statin. Low-dose statins in combination with nonstatin therapy, or the exclusive use of nonstatin therapy, is advised only when the patient is unable or unwilling to take statins.

\section{Conclusion}

Heart disease remains the leading cause of death in women. Dyslipidemia is highly prevalent among women. Women undergo a number of hormonal changes throughout their lives that have significant effects on lipoprotein metabolism. With menopause, women experience a worsening of their lipid profile, with transition to higher and more atherogenic dyslipidemia. While hormone replacement therapy is associated with a more favorable lipid profile, it does not reduce the risk of CHD. Although women tend to have a higher baseline HDL-C than age-matched and weight-matched men, a clinician should not simply assume that a high HDL-C will mask the risk associated with a high LDL-C or non-HDL-C. Women in the primary prevention setting should undergo risk assessment, with statin therapy initiated based on guideline recommendations. Women with established atherosclerotic cardiovascular disease should be treated with a statin. Statin therapy has been shown to be efficacious in women. Statins and other lipid-modifying medications should be used in a manner that is consistent with regional guidelines.

\section{Disclosure}

Peter P Toth is part of the Speakers Bureau, Amarin, AstraZeneca, GSK, Kowa, Merck and a consultant for Aegerion, Amgen, AstraZeneca, Atherotech, Kowa, 
Liposcience, Merck. The authors report no other conflicts of interest in this work.

\section{References}

1. Kochanek KD, Xu JQ, Murphy SL, Miniño AM, Kung HC. Deaths: final data for 2009. Natl Vital Stat Rep. 2011;60(3).

2. Roger VL, Go AS, Lloyd-Jones DM, et al. Heart disease and stroke statistics - 2011 update. A report from the American Heart Association. Circulation. 2011;123(4):e18-e209.

3. Lerner DJ, Kannel WB. Patterns of coronary heart disease morbidity and mortality in the sexes: a 26-year follow-up of the Framingham population. Am Heart J. 1986;111(2):383-390.

4. Keys A, Menotti A, Aravanis C, et al. The seven countries study: 2,289 deaths in 15 years. Prev Med. 1984;13(2):141-154.

5. Kannel WB, Castelli WP, Gordon T. Cholesterol in the prediction of atherosclerotic disease. Ann Intern Med. 1979;90(1):85.

6. Sempos CT, Cleeman JI, Carroll MD, et al. Prevalence of high blood cholesterol among US adults: an update based on guidelines from the Second Report of the National Cholesterol Education Program Adult Treatment Panel. JAMA. 1993;269(23):3009-3014.

7. Mostaghel E, Waters D. Women do benefit from lipid lowering: latest clinical trial data. Cardiol Rev. 2003;11(1):4-12.

8. [No authors listed]. Third Report of the National Cholesterol Education Program (NCEP) Expert Panel on Detection, Evaluation, and Treatment of High Blood Cholesterol in Adults (Adult Treatment Panel III) final report. Circulation. 2002;106(25):3143-3421.

9. Genest J, McPherson R, Frohlich J, et al. 2009 Canadian Cardiovascular Society/Canadian guidelines for the diagnosis and treatment of dyslipidemia and prevention of cardiovascular disease in the adult - 2009 recommendations. Can J Cardiol. 2009;25(10):567-579.

10. European Association for Cardiovascular Prevention and Rehabilitation, Reiner Z, Catapano AL, De Backer G, et al; ESC Committee for Practice Guidelines (CPG) 2008-2010 and 2010-2012 Committees. ESC/EAS Guidelines for the management of dyslipidaemias: the Task Force for the management of dyslipidaemias of the European Society of Cardiology (ESC) and the European Atherosclerosis Society (EAS). Eur Heart J. 2011;32(14):1769-1818.

11. Clarke R, Peden JF, Hopewell JC, et al. Genetic variants associated with Lp(a) lipoprotein level and coronary disease. $N$ Engl $J$ Med. 2009;361(26):2518-2528.

12. Emerging Risk Factors Collaboration, Erqou S, Kaptoge S, Perry PL, et al. Lipoprotein(a) concentration and the risk of coronary heart disease, stroke, and nonvascular mortality. JAMA. 2009;302(4):412-423.

13. Bays HE, Toth PP, Kris-Etherton PM, et al. Obesity, adiposity, and dyslipidemia: a consensus statement from the National Lipid Association. J Clin Lipidol. 2013;7(4):304-383.

14. Knopp RH. Cardiovascular effects of endogenous and exogenous sex hormones over a woman's lifetime. Am J Obstet Gynecol. 1988; 158(6 Pt 2):1630-1643.

15. Bittner V. Lipoprotein abnormalities related to women's health. Am J Cardiol. 2002;90(8A):77i-84i.

16. Lloyd JK. Hyperlipidaemia in children. Br Heart J. 1975;37(2): 105-114.

17. Freedman DS, Bowman BA, Otvos JD, Srinivasan SR, Berenson GS. Levels and correlates of LDL and VLDL particle sizes among children: the Bogalusa Heart Study. Atherosclerosis. 2000;152(2): 441-449.

18. Kreisberg RA, Kasim S. Cholesterol metabolism and aging. Am JMed. 1987;82(1B):54-60.

19. Freedman DS, Bowman BA, Srinivasan SR, Berenson GS, Otvos JD. Distribution and correlates of high-density lipoprotein subclasses among children and adolescents. Metabolism. 2001;50(3):370-376.

20. Desoye G, Schweditsch MO, Pfeiffer KP, Zechner R, Kostner GM. Correlation of hormones with lipid and lipoprotein levels during normal pregnancy and postpartum. J Clin Endocrinol Metab. 1987;64(4): 704-712.
21. Lippi G, Albiero A, Montagnana M, et al. Lipid and lipoprotein profile in physiological pregnancy. Clin Lab. 2007;53(3-4):173-177.

22. Mazurkiewicz JC, Watts GF, Warburton FG, Slavin BM, Lowy C, Koukkou E. Serum lipids, lipoproteins and apolipoproteins in pregnant non-diabetic patients. J Clin Pathol. 1994;47(8):728-731.

23. Van Stiphout WA, Hofman A, de Bruijn AM. Serum lipids in young women before, during, and after pregnancy. Am J Epidemiol. 1987;126(5):922-928.

24. Lewis CE, Funkhouser E, Raczynski JM, Sidney S, Bild DE, Howard BV. Adverse effect of pregnancy on high density lipoprotein (HDL) cholesterol in young adult women: the CARDIA study. $A m J$ Epidemiol. 1996;144(3):247-254.

25. Zechner R, Desoye G, Schweditsch MO, Pfeiffer KP, Kostner GM. Fluctuations of plasma lipoprotein-A concentrations during pregnancy and post partum. Metabolism. 1986;35(4):333-336.

26. Bonithon-Kopp C, Scarabin P-Y, Darne B, Malmejac A, Guize L. Menopause-related changes in lipoproteins and some other cardiovascular risk factors. Int J Epidemiol. 1990;19(1):42-48.

27. Wu Z, Wu X, Zhang Y. Relationship of menopausal status and sex hormones to serum lipids and blood pressure. Int $J$ Epidemiol. 1990;19(2):297-302.

28. Akahoshi M, Soda M, Nakashima E, Shimaoka K, Seto S, Yano K. Effects of menopause on trends of serum cholesterol, blood pressure, and body mass index. Circulation. 1996;94(1):61-66.

29. Hjortland MC, McNamara PM, Kannel WB. Some atherogenic concomitants of menopause: the Framingham study. Am J Epidemiol. 1976;103(3):304-311.

30. Carr MC, Kim KH, Zambon A, et al. Changes in LDL density across the menopausal transition. J Investig Med Off Publ Am Fed Clin Res. 2000;48(4):245-250.

31. Matthews KA, Meilahn E, Kuller LH, Kelsey SF, Caggiula AW, Wing RR. Menopause and risk factors for coronary heart disease. N Engl J Med. 1989;321(10):641-646.

32. Lip GY, Blann AD, Jones AF, Beevers DG. Effects of hormone-replacement therapy on hemostatic factors, lipid factors, and endothelial function in women undergoing surgical menopause: implications for prevention of atherosclerosis. Am Heart J. 1997;134(4): 764-771.

33. Jenner JL, Ordovas JM, Lamon-Fava S, et al. Effects of age, sex, and menopausal status on plasma lipoprotein(a) levels. The Framingham Offspring Study. Circulation. 1993;87(4):1135-1141.

34. Hamman RF, Bennett PH, Miller M. The effect of menopause on serum cholesterol in American (Pima) Indian Women. Am J Epidemiol. 1975;102(2):164-169.

35. Fotherby K. Oral contraceptives and lipids. BMJ. 1989;298(6680): 1049-1050.

36. Tikkanen MJ, Nikkilä EA, Kuusi T, Sipinen S. High density lipoprotein-2 and hepatic lipase: reciprocal changes produced by estrogen and norgestrel. J Clin Endocrinol Metab. 1982;54(6):1113-1117.

37. Realini JP, Goldzieher JW. Oral contraceptives and cardiovascular disease: a critique of the epidemiologic studies. Am J Obstet Gynecol. 1985;152(6 Pt 2):729-798.

38. Lewis MA. Myocardial infarction and stroke in young women: what is the impact of oral contraceptives? Am J Obstet Gynecol. 1998; 179(3 Pt 2):S68-S77.

39. Cauley JA, LaPorte RE, Kuller LH, Bates M, Sandler RB. Menopausal estrogen use, high density lipoprotein cholesterol subfractions and liver function. Atherosclerosis. 1983;49(1):31-39.

40. Meade TW. Randomised comparison of oestrogen versus oestrogen plus progestogen hormone replacement therapy in women with hysterectomy. BMJ. 1996;312(7029):473-478.

41. Wakatsuki A, Ikenoue N, Okatani Y, Fukaya T. Estrogen-induced small low density lipoprotein particles may be atherogenic in postmenopausal women. J Am Coll Cardiol. 2001;37(2):425-430.

42. Soma M, Fumagalli R, Paoletti R, et al. Plasma Lp(a) concentration after oestrogen and progestagen in postmenopausal women. Lancet. 1991;337(8741):612. 
43. Edmunds E, Lip GYH. Cardiovascular risk in women: the cardiologist's perspective. QJM. 2000;93(3):135-145.

44. Grodstein F, Stampfer MJ, Colditz GA, et al. Postmenopausal hormone therapy and mortality. N Engl J Med. 1997;336(25):1769-1775.

45. Bush TL, Barrett-Connor E, Cowan LD, et al. Cardiovascular mortality and noncontraceptive use of estrogen in women: results from the Lipid Research Clinics Program Follow-up Study. Circulation. 1987; 75(6):1102-1109.

46. Grady D, Rubin SM, Petitti DB, et al. Hormone therapy to prevent disease and prolong life in postmenopausal women. Ann Intern Med. 1992;117(12):1016-1037.

47. Hulley S, Grady D, Bush T, et al. Randomized trial of estrogen plus progestin for secondary prevention of coronary heart disease in postmenopausal women. Heart and Estrogen/progestin Replacement Study (HERS) Research Group. JAMA. 1998;280(7):605-613.

48. Anderson GL, Limacher M, Assaf AR, et al. Effects of conjugated equine estrogen in postmenopausal women with hysterectomy: the Women's Health Initiative randomized controlled trial. JAMA 2004;291(14):1701-1712.

49. Mosca L, Appel LJ, Benjamin EJ, et al. Evidence-based guidelines for cardiovascular disease prevention in women. $J \mathrm{Am}$ Coll Cardiol. 2004;43(5):900-921.

50. The Emerging Risk Factors Collaboration. Major lipids, apolipoproteins, and risk of vascular disease. JAMA. 2009;302(18):1993-2000.

51. Bass KM, Newschaffer CJ, Klag MJ, Bush TL. Plasma lipoprotein levels as predictors of cardiovascular death in women. Arch Intern Med. 1993;153(19):2209-2216.

52. Hokanson JE, Austin MA. Plasma triglyceride level is a risk factor for cardiovascular disease independent of high-density lipoprotein cholesterol level: a meta-analysis of population-based prospective studies. J Cardiovasc Risk. 1996;3(2):213-219.

53. Kamigaki AS, Siscovick DS, Schwartz SM, et al. Low density lipoprotein particle size and risk of early-onset myocardial infarction in women. Am J Epidemiol. 2001;153(10):939-945.

54. Shlipak MG, Simon JA, Vittinghoff E, et al. Estrogen and progestin, lipoprotein(a), and the risk of recurrent coronary heart disease events after menopause. JAMA. 2000;283(14):1845-1852.

55. Ornish D, Scherwitz LW, Billings JH, et al. Intensive lifestyle changes for reversal of coronary heart disease. JAMA. 1998;280(23): 2001-2007.

56. Estruch R, Ros E, Salas-Salvadó J, et al. Primary prevention of cardiovascular disease with a Mediterranean diet. $N$ Engl $J$ Med. 2013;368(14):1279-1290.

57. Howard BV, Van Horn L, Hsia J, et al. Low-fat dietary pattern and risk of cardiovascular disease: the Women's Health Initiative Randomized Controlled Dietary Modification Trial. JAMA. 2006; 295(6):655-666

58. Kastelein JJP, Akdim F, Stroes ESG, et al. Simvastatin with or without ezetimibe in familial hypercholesterolemia. $N$ Engl J Med. 2008;358(14):1431-1443.

59. Shepherd J, Cobbe SM, Ford I, et al. Prevention of coronary heart disease with pravastatin in men with hypercholesterolemia. West of Scotland Coronary Prevention Study Group. $N$ Engl J Med. 1995;333(20):1301-1307.

60. Sacks FM, Pfeffer MA, Moye LA, et al. The effect of pravastatin on coronary events after myocardial infarction in patients with average cholesterol levels. Cholesterol and Recurrent Events Trial investigators. N Engl J Med. 1996;335(14):1001-1009.

61. Downs JR, Clearfield M, Weis S, et al. Primary prevention of acute coronary events with lovastatin in men and women with average cholesterol levels: results of AFCAPS/TexCAPS. JAMA. 1998;279(20): 1615-1622.

62. [No authors listed]. Randomised trial of cholesterol lowering in 4444 patients with coronary heart disease: the Scandinavian Simvastatin Survival Study (4S). Lancet. 1994;344(8934):1383-1389.

63. [No authors listed]. MRC/BHF Heart Protection Study of cholesterol lowering with simvastatin in 20,536 high-risk individuals: a randomised placebo-controlled trial. Lancet. 2002;360(9326):7-22.
64. LIPID Study Group (Long-term Intervention with Pravastatin in Ischaemic Disease). Long-term effectiveness and safety of pravastatin in 9014 patients with coronary heart disease and average cholesterol concentrations: the LIPID trial follow-up. Lancet. 2002;359(9315): $1379-1387$.

65. LaRosa JC, Grundy SM, Waters DD, et al. Intensive lipid lowering with atorvastatin in patients with stable coronary disease. $N$ Engl $J$ Med. 2005;352(14):1425-1435.

66. Cannon $\mathrm{CP}$, Braunwald $\mathrm{E}, \mathrm{McCabe} \mathrm{CH}$, et al. Intensive versus moderate lipid lowering with statins after acute coronary syndromes. $N$ Engl $J$ Med. 2004;350(15):1495-1504.

67. Cannon CP, Steinberg BA, Murphy SA, Mega JL, Braunwald E. Metaanalysis of cardiovascular outcomes trials comparing intensive versus moderate statin therapy. J Am Coll Cardiol. 2006;48(3):438-445.

68. Frick MH, Elo O, Haapa K, et al. Helsinki Heart Study: primaryprevention trial with gemfibrozil in middle-aged men with dyslipidemia. Safety of treatment, changes in risk factors, and incidence of coronary heart disease. N Engl J Med. 1987;317(20):1237-1245.

69. LaRosa JC, He J, Vupputuri S. Effect of statins on risk of coronary disease: a meta-analysis of randomized controlled trials. JAMA. 1999;282(24):2340-2346.

70. Wals JE, Pignone M. Drug treatment of hyperlipidemia in women. JAMA. 2004;291(18):2243-2252.

71. Mora S, Glynn RJ, Hsia J, MacFadyen JG, Genest J, Ridker PM. Statins for the primary prevention of cardiovascular events in women with elevated high-sensitivity C-reactive protein or dyslipidemia: results from the Justification for the Use of Statins in Prevention: An Intervention Trial Evaluating Rosuvastatin (JUPITER) and meta-analysis of women from primary prevention trials. Circulation. 2010;121(9):1069-1077.

72. Robins SJ. Relation of gemfibrozil treatment and lipid levels with major coronary events: VA-HIT: a randomized controlled trial. JAMA. 2001;285(12):1585-1591.

73. Baigent C, Keech A, Kearney PM, et al. Efficacy and safety of cholesterol-lowering treatment: prospective meta-analysis of data from 90,056 participants in 14 randomised trials of statins. Lancet. 2005;366(9493):1267-1278

74. ACCORD Study Group, Ginsberg HN, Elam MB, et al. Effects of combination lipid therapy in type 2 diabetes mellitus. $N$ Engl $\mathrm{J}$ Med. 2010;362(17):1563-1574

75. Boden WE, Probstfield JL, Anderson T, et al. Niacin in patients with low HDL cholesterol levels receiving intensive statin therapy. $N$ Engl J Med. 2011;365(24):2255-2267.

76. HPS2-THRIVE Collaborative Group. HPS2-THRIVE randomized placebocontrolled trial in 25673 high-risk patients of ER niacin/laropiprant: trial design, pre-specified muscle and liver outcomes, and reasons for stopping study treatment. Eur Heart J. 2013;34(17):1279-1291.

77. The Lipid Research Clinics Coronary Primary Prevention Trial results. I. Reduction in incidence of coronary heart disease. JAMA. 1984;251(3):351-364.

78. Cannon CP, Giugliano RP, Blazing MA, et al. Rationale and design of IMPROVE-IT (IMProved Reduction of Outcomes: Vytorin Efficacy International Trial): comparison of ezetimbe/simvastatin versus simvastatin monotherapy on cardiovascular outcomes in patients with acute coronary syndromes. Am Heart J. 2008;156(5):826-832.

79. Baigent C, Landray MJ, Reith C, et al. The effects of lowering LDL cholesterol with simvastatin plus ezetimibe in patients with chronic kidney disease (Study of Heart and Renal Protection): a randomised placebo-controlled trial. Lancet. 2011;377(9784):2181-2192.

80. Jones PH, Davidson MH. Reporting rate of rhabdomyolysis with fenofibrate + statin versus gemfibrozil + any statin. Am J Cardiol. 2005;95(1): $120-122$.

81. Prueksaritanont T, Zhao JJ, Ma B, et al. Mechanistic studies on metabolic interactions between gemfibrozil and statins. $J$ Pharmacol Exp Ther. 2002;301(3):1042-1051.

82. Prueksaritanont T, Subramanian R, Fang X, et al. Glucuronidation of statins in animals and humans: a novel mechanism of statin lactonization. Drug Metab Dispos Biol Fate Chem. 2002;30(5):505-512. 
83. Stone NJ, Robinson J, Lichtenstein AH, et al. 2013 ACC/AHA Guideline on the Treatment of Blood Cholesterol to Reduce Atherosclerotic Cardiovascular Risk in Adults: A Report of the American College of Cardiology/American Heart Association Task Force on Practice Guidelines. Circulation. November 12, 2013. [Epub ahead of print.]

84. Goff DC Jr, Lloyd-Jones DM, Bennett G, et al. 2013 ACC/AHA Guideline on the Assessment of Cardiovascular Risk: A Report of the American College of Cardiology/American Heart Association Task Force on Practice Guidelines. Circulation. November 12, 2013. [Epub ahead of print.]

85. Downs JR, Clearfield M, Weis S, et al. Primary prevention of acute coronary events with lovastatin in men and women with average cholesterol levels: results of AFCAPS/TexCAPS. Air Force/Texas Coronary Atherosclerosis Prevention Study. JAMA. 1998;279:1615-1622.
86. Scandinavian Simvastatin Survival Study Group. Randomised trial of cholesterol lowering in 4444 patients with coronary heart disease: the Scandinavian Simvastatin Survival Study (4S). Lancet.1994;344:1383-1389.

87. Sacks FM, Pfeffer MA, Moye LA, et al. The effect of pravastatin on coronary events after myocardial infarction in patients with average cholesterol levels. Cholesterol and Recurrent Events Trial investigators. N Engl J Med. 1996;335:1001-1009.

88. Prevention of Cardiovascular Events and Death with Pravastatin in Patients with Coronary Heart Disease and a Broad Range of Initial Cholesterol Levels N Engl J Med. 1998;339:1349-1357.

89. Heart Protection Study Collaborative Group. MRC/BHF Heart Protection Study of cholesterol lowering with simvastatin in 20536 high-risk individuals: a randomised placebo controlled trial. Lancet. 2002;360:7-22.

International Journal of Women's Health

\section{Publish your work in this journal}

The International Journal of Women's Health is an international, peerreviewed open-access journal publishing original research, reports, editorials, reviews and commentaries on all aspects of women's healthcare including gynecology, obstetrics, and breast cancer. The manuscript management system is completely online and includes

\section{Dovepress}

a very quick and fair peer-review system, which is all easy to use. Visit http://www.dovepress.com/testimonials.php to read real quotes from published authors.

Submit your manuscript here: http://www.dovepress.com/international-journal-of-womens-health-journal 